\title{
Effect of co-contaminated soil mixtures as fixed/fluidized bed media on pollutants emission under thermal treatment
}

\author{
U. Samaksaman ${ }^{1}$ J.-H. Kuo ${ }^{1}$ T.-H. Peng ${ }^{1}$ M.-Y. Wey ${ }^{1}$
}

Received: 16 May 2015/Revised: 9 September 2015/Accepted: 21 September 2015/Published online: 7 October 2015

(C) Islamic Azad University (IAU) 2015

\begin{abstract}
Thermal treatment of soil polluted by lube oil and heavy metals (cadmium, chromium, copper, and lead) was carried out by using a laboratory-scale incinerator. The effect of co-contaminated soil mixtures as fixed/fluidized bed media was studied with different ratios of sand bed amount to soil feeding. Additionally, the effect of soil moisture content on incineration system was further investigated. The reduction in air input altered the mode of fluidized bed to fixed bed which resulted in an increase in organic pollutants such as benzene, toluene, ethylbenzene, xylene, and polycyclic aromatic hydrocarbons. The combustion efficiency of fixed bed mode was observed to be relatively high at a lower ratio of sand bed amount to soil feeding, whereas high combustion efficiency was found in fluidized bed mode at a higher ratio of sand bed amount to soil feeding. Much higher concentration of organic pollutants in both gas phase and bottom ash is found under a higher soil moisture content. In addition, the increase in moisture content has resulted in an increase in lead, cadmium, and chromium in fly ash while copper was decreased. An important consideration is that the partitioning of heavy metals was randomly distributed in particle sizes of bottom ash. The highest concentration of heavy metals was deposited on fine-sized particle. The distribution of heavy metals in medium-sized and coarse-sized particles to form eutectic species might be produced by the soil-sand aggregation.
\end{abstract}

Keywords Heavy metals - Incineration · Moisture . Organic pollutants

\section{J.-H. Kuo \\ jhkuo@gdut.edu.cn}

1 Department of Environmental Engineering, National Chung Hsing University, Taichung 402, Taiwan, ROC

\section{Introduction}

The presence of soils polluted by used lube oils is becoming more widespread. It poses a threat to the environment because the used lube oil contains toxic heavy metals which resulted from oil additives, mechanical wear, and chemical corrosion (Bradl 2005; Hu et al. 2013). Different kinds of anthropogenic activities such as improper disposal of refinery wastes, leaking petroleum storage tanks, former train stations and railroads, industrialized areas, landfills, and mining sites have all become the source of lube oils and heavy metals (Alloway 2013; Jones et al. 2013; Nordmark et al. 2011; Rutkowska et al. 2015; Torres et al. 2007; Osman 2014; Wiłkomirski et al. 2011). In this study, this soil is called co-contaminated soil. The selection of a remediation method depends on technical feasibility such as concentration and type of pollutants, the soil type, the local availability of remediation processes, and economic aspects (Koning et al. 2000). The use of bio-remediation for treating co-contaminated soils has to concede in long-term degradation (Abdulsalam et al. 2011; Alisi et al. 2009; Almeida et al. 2013). Since the treatments of co-contaminated soils are limited, it is widely agreed that multiple costly techniques are required (Khan et al. 2004). A number of investigations have shown that thermal treatment (thermal desorption, incineration, pyrolysis, gasification, and vitrification) is one of the effective processes for complex substances remediation (González-Corrochano et al. 2012; Qi et al. 2014; Qin et al. 2015; Taube et al. 2008; Van Caneghem et al. 2012).

Incineration is an attractive method for treating a wide range of hazardous wastes. The most detailed study of soil incineration process to date reached the goals of completely destroying the organic pollutants and considerably reducing the toxicity (Chen and Yan 2012). Moreover, incineration can be considered as a simple technique for energy production and can be used for almost of all combustible materials, with the 
advantages of being harmless and environmentally friendly (Eldabbagh et al. 2005; Wu et al. 2014). Currently, soil incineration may not be clear in the issue of economic feasibility (Bulmău et al. 2014). Soil incineration is an ex situ treatment that requires further procedures such as the construction of incinerator plant and air pollution control devices, to maintain the operating temperature using auxiliary fuels, to use electricity for running pumps and fans, and other processes such as soil excavation, dewatering process, and transportation. Nevertheless, in the view of a time, cost, land consumption, site located in urban area, and so on, the soil incineration perhaps is a good choice and a better selection than other remediation methods.

The appearance of pollutants emission and by-products as disadvantages of thermal treatment of toxic contaminants in soils has not been neglected. Previous works reported that the combustion of used lube oils was detected to be coincident with 30 volatile and 170 semi-volatile compounds such as benzene, toluene, ethylbenzene, xylene (BTEX), and polycyclic aromatic hydrocarbons (PAHs) (Fuentes et al. 2007; Mascolo et al. 2006). Furthermore, metal elements that could not be destroyed by combustion were found. Volatile metals were volatilized and further deposited on particles in the exhaust gas. Non-volatile metals were formed with the fraction of clay or sand matrix (Bolan et al. 2014; Huang et al. 2011).

The effects of operating temperature, heating rate, treatment time, pollutant type, and soil type have been thoroughly studied (Bulmău et al. 2014; Falciglia et al. 2011; Ho et al. 1995). In cases of hot-sand bed reactor, the motivation of sand bed predominates over combustion and mixing efficiencies (Mininni et al. 2004). The increase in air input alters stationary bed (or fixed bed) to fluidized bed regime. Previous studies pointed out that the increase in fluidization air velocity reduced pollutants such as flue gas, acid gases, BTEX, PAHs (Peng and Lin 2014) and decreased the possibility of an agglomeration/defluidization of sand bed (Kuo et al. 2010).

A rise in the sand bed height with different particle sizes affects the behaviors of bed material in several approaches (Lin and Wey 2004a). Among these, two possible ways can be summarized: Firstly, there is an extended bed material from the bottom bed to the upper bed in the furnace, causing change in sand bed's hydrodynamics. Secondly, there is a redistribution of bed material, causing change in the upper bed to have a smaller particle size and reduced space above sand bed (freeboard or splash zone). Previous studies have investigated the effect of sand bed height tended to increase heavy metals collection (Lin and Yeh 2010), and the amount of sand bed in a fluidized bed reactor also influenced the removal efficiencies of heavy metals and particles (Nowak et al. 2011). Because the ash composition of co-contaminated soil (up to $95 \mathrm{wt} \%$ ) is significantly high (Samaksaman et al. 2015), soil incineration led to elevating the sand bed (slag) height during thermal treatment. Results from earlier studies have suggested that the addition of inert materials such as clay, aluminum, silica, kaolinite was a way to increase the sources of alternative bed material (Kuo et al. 2008) and could prevent any kinds of problems including combustion and removal efficiencies, pollutants, even improved hydrodynamics behaviors.

Moisture content is a direct factor in the heat balance of soil incineration system. The proportions of moisture content to the weight of soil are commonly in the range of $15-40 \%$ (in wet basis) (Acharya et al. 1996) and have changed dramatically during dewatering process. At high combustion temperatures, metals with high vapor pressures, such as mercury $(\mathrm{Hg})$ and cadmium $(\mathrm{Cd})$, and metals with lower vapor pressures, such as lead $(\mathrm{Pb})$ and zinc $(\mathrm{Zn})$, are volatilized at their boiling points and somewhat affected by water evaporation. Copper $(\mathrm{Cu})$ was stable in the bottom ash as copper oxides (Meng et al. 2012). Moisture content has a significant effect on metals concentration of the partitioning of residues. The maximum fixation rates for $\mathrm{Cd}, \mathrm{Cu}$, chromium $(\mathrm{Cr})$, nickel $(\mathrm{Ni})$, manganese $(\mathrm{Mn})$, and $\mathrm{Zn}$ were achieved when the $55 \%$ of moisture content of sludge was combusted (Chen and Yan 2012). Additionally, the results of thermodynamics calculation indicated that the moisture content influenced heavy metals behaviors during combustion which changed metal chloride forms to metal oxide forms (Zhang et al. 2012).

It would be interesting to examine the thermal treatment of soil polluted by lube oil and heavy metals $(\mathrm{Cd}, \mathrm{Cr}, \mathrm{Cu}$, and $\mathrm{Pb})$ in detail. This study assesses the impact of different modes of fixed bed and fluidized bed incinerations with different ratios of sand bed amount to soil feeding $\left(S_{\mathrm{a}} / S_{\mathrm{f}}\right)$. The effect of moisture content was carried out using the fluidized bed incineration. Most of experiments employed a laboratoryscale reactor. This work also evaluates the effects of different operating parameters on pollutant emissions such as carbon monoxide ( $\mathrm{CO})$, carbon dioxide $\left(\mathrm{CO}_{2}\right)$, BTEX, PAHs, fly ash, and bottom ash. The concentrations of heavy metals in fly ash and the distribution of particle sizes of bottom ash were analyzed. X-ray techniques were used to investigate the characterizations of ash samples. Important information is that all experimental studies were performed during February-May 2014 at the location of Taichung South District, Taichung city, Republic of China (Taiwan).

\section{Materials and methods}

\section{Preparation of artificial co-contaminated soil}

The soil used in this study was collected from an area in National Chung Hsing University. Concentration of heavy metals in the soil has previously been analyzed and the details of physical properties could be referred from a previous study (Samaksaman et al. 2015). The concentration of Cd was not 
found in the soil. $\mathrm{Cr}, \mathrm{Cu}$, and $\mathrm{Pb}$ were $40.67,13.25$, and $32.47 \mathrm{mg} / \mathrm{kg}$, respectively. The soil was crushed and sieved through a screening tray (Tyler standard \#50) with an average particle size diameter of $0.75 \mathrm{~mm}$. A kilogram of soil was mixed with $0.15 \mathrm{wt} \%$ of metal nitrate diluted in deionized water, which includes $\mathrm{Cd}(\mathrm{II}), \mathrm{Cr}(\mathrm{III}), \mathrm{Cu}(\mathrm{II})$, and $\mathrm{Pb}(\mathrm{II})$. Slurry soil was evaporated in a vacuum drying oven at $110{ }^{\circ} \mathrm{C}$ for overnight. Further, heavy metals contaminated soil was blended with $5 \mathrm{wt} \%$ of lube oil (Yamaha SAE $85 \mathrm{~W}-140$ G-130) diluted in dichloromethane (DCM) and dried at $75{ }^{\circ} \mathrm{C}$ for overnight. The concentration of lube oil was approximately $50000 \mathrm{mg} / \mathrm{kg}$. Cd was $1435 \mathrm{mg} / \mathrm{kg}$. Cr was $1325 \mathrm{mg} /$ $\mathrm{kg}$. Cu was $1212 \mathrm{mg} / \mathrm{kg}$. Pb was $1256 \mathrm{mg} / \mathrm{kg}$. Co-contaminated soil was sieved and kept for 2 weeks before the tests.

\section{Apparatus}

The diagram of a laboratory-scale incinerator is shown in Fig. 1. A preheater was located at the bottom of the combustion chamber made of $3 \mathrm{~mm}$ of thickness of stainless steel (AISI 310) with $4.83 \mathrm{~cm}$ inner diameter and $80 \mathrm{~cm}$ length. A distributor was located inside combustion chamber. The incinerator is enclosed by electric heaters equipped with packing ceramics to thermally insulate the system. The operating temperature was monitored by devices such as thermocouples and a proportional-integral-derivative controller. An ash collector, a filtration reactor, an induced draft fan, and a wet scrubber were connected in series as an air pollution control device (APCD) for preventing dust or any kinds of pollutants emitted.

\section{Methodology}

The sets of experiments are listed in Table 1 . The density of sand was $2600 \mathrm{~kg} / \mathrm{m}^{3}$. The average particle size of sand

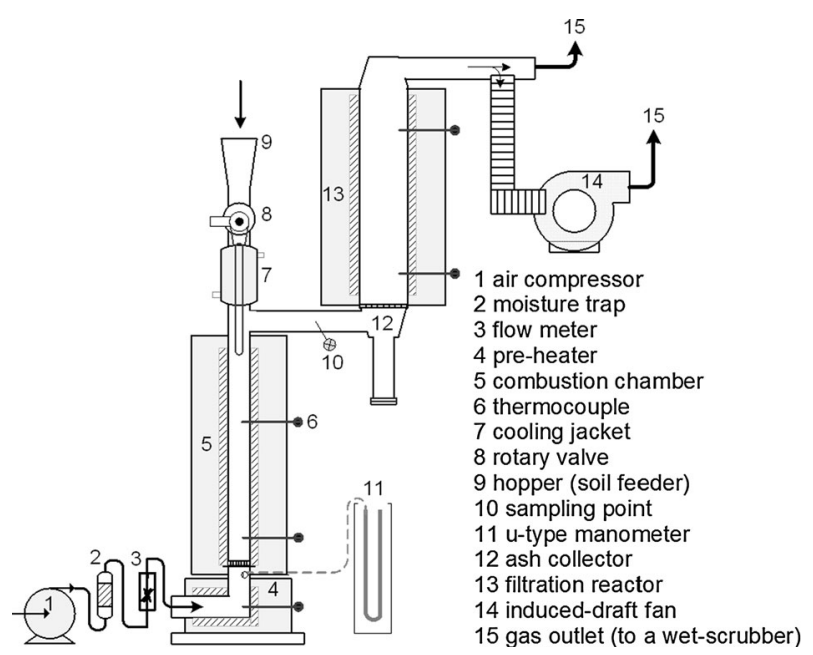

Fig. 1 A schematic diagram of a laboratory-scale incinerator
Table 1 Experimental parameters of this study

\begin{tabular}{ll}
\hline Item & Parameters \\
\hline Reactor & $\begin{array}{l}\text { Laboratory-scale fixed/fluidized bed } \\
\text { incinerator }\end{array}$ \\
Operating time $(\mathrm{min})$ & 40 \\
Temperature $\left({ }^{\circ} \mathrm{C}\right)$ & 800 \\
Operating conditions & $0.75 / 1,1.0 / 1,1.5 / 1,2.0 / 1$ \\
$S_{\mathrm{a}} / S_{\mathrm{f}}\left(g_{\text {sand }} / g_{\text {soil }}\right)$ & $(93.7 / 125,125 / 125,187.5 / 125,250 / 125)$ \\
Reactor mode & Fixed bed, fluidized bed \\
Soil moisture content & $1,5,15,25$ (wet basis) \\
$\quad(\%)$ & APCD included an ash collector, a \\
Air pollution control & filtration reactor, an induced draft fan, \\
devices (APCDs) & and a wet scrubber \\
\end{tabular}

$S_{\mathrm{a}} / S_{\mathrm{f}}=$ The ratio of sand bed amount to soil feeding

$\mathrm{g}_{\text {sand }} / \mathrm{g}_{\text {soil }}=$ The ratio of the weight of sand bed ( $\mathrm{g}$ ) to the weight of soil feeding $(\mathrm{g})$

was $920 \mu \mathrm{m}$ in diameter. At $800{ }^{\circ} \mathrm{C}$, the minimum fluidization air velocity $\left(U_{\mathrm{mf}}\right)$ was $10.5 \mathrm{~cm} / \mathrm{s}$. Two operating modes of fixed bed $\left(0.9 U_{\mathrm{mf}}=9.45 \mathrm{~cm} / \mathrm{s}\right)$ and fluidized bed $\left(1.3 U_{\mathrm{mf}}=13.65 \mathrm{~cm} / \mathrm{s}\right)$ were studied with different ratios of $S_{\mathrm{a}} / S_{\mathrm{f}}$. Ratios of $S_{\mathrm{a}} / S_{\mathrm{f}}$ were $0.75 / 1,1.0 / 1,1.5 / 1$, and 2.0/1, which were represented in ratios of the weight of sand bed (g) to the weight of soil feeding $(\mathrm{g})$ of 93.7/125, 125/125, $187.5 / 125$, and $250 / 125$, respectively. Co-contaminated soil was continuously fed at a constant rate of $3.2 \mathrm{~g} / \mathrm{min}$. In addition, the study of moisture content was performed under the ordinary fluidized bed incineration condition (e.g., the operating temperature of $800{ }^{\circ} \mathrm{C}, S_{\mathrm{a}} / S_{\mathrm{f}}$ ratio of $1.0 / 1(125 \mathrm{~g} / 125 \mathrm{~g})$, and fluidization air velocity of $13.65 \mathrm{~cm} / \mathrm{s}$ ). The soil moisture content was varied from 1 to $25 \%$. During the tests, fly ash and gaseous samples were sampled according to the U.S. EPA method 5 (Wey et al. 2000) and U.S. EPA modified method 5 (Wey et al. 2006), respectively. Four samples of fly ash and three samples of BTEX and PAHs collections were analyzed under the isokinetic condition. Fly ash was sampled by a glass filter (Whatman GF/A $47 \mathrm{~mm}$ ). BTEX and PAHs in the gaseous phase were collected by using $5 \mathrm{~g}$ of Amberlite XAD-4 absorber (Fluka). Absorber was contained in a glass cartridge which was connected in a series of glass containers in the sampling train. Flue gas was continuously analyzed by a portable multi-gas analyzer (Horiba PG-250). The bottom ash (sand bed and treated soil) was collected after the combustion chamber cooled at room temperature and mixed as homogeneity sample in a circular box. The bottom ash was randomly sampled for analyses. Particle sizes of bottom ash were divided into three parts: fine-sized (53-297 $\mu \mathrm{m})$, medium-sized $(297-422 \mu \mathrm{m})$, and coarsesized particles $(422-1000 \mu \mathrm{m})$. 

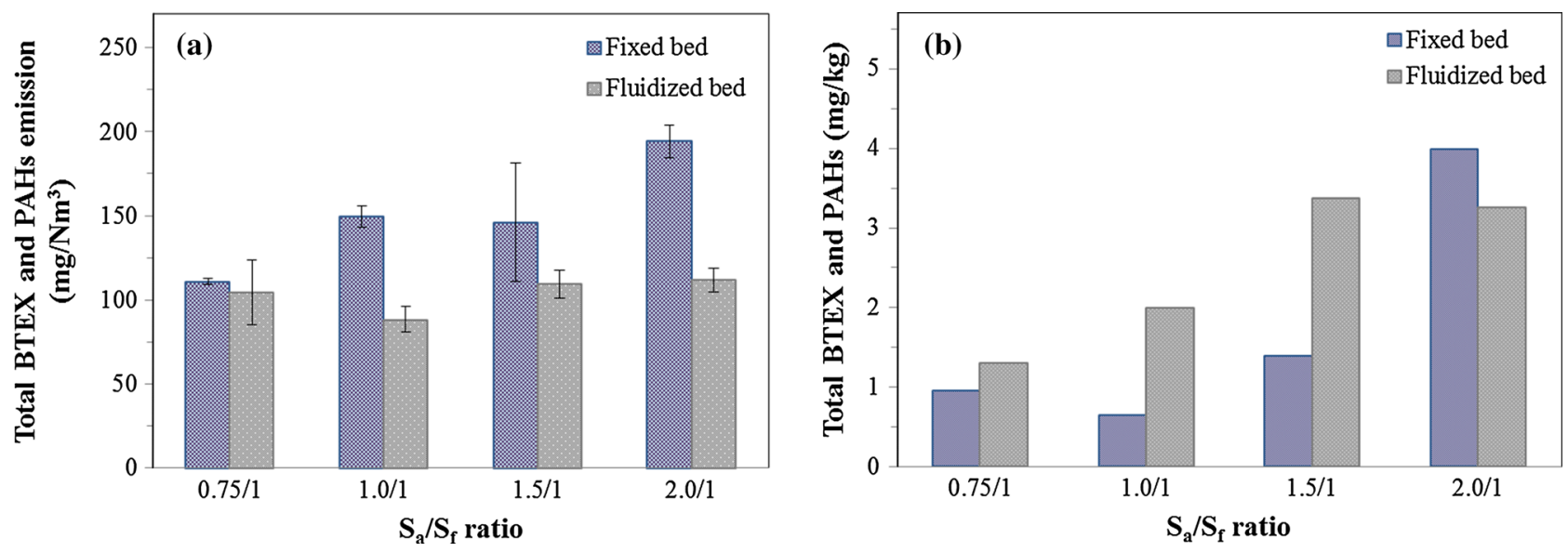

Fig. 2 Total concentration of BTEX and PAHs emitted from fixed bed and fluidized bed with different ratios of $S_{\mathrm{a}} / S_{\mathrm{f}}$; a gaseous emission and b bottom ash

\section{Analysis and characterization}

BTEX and PAHs extraction was performed by a mixture of solvents (hexane/DCM $=1: 1$ ), for $20 \mathrm{~h}$ in the Soxhlet extraction units. Then, the extracted solvent was purified and concentrated by Kuderna-Danish apparatus (K-D method). The concentrations of BTEX and 16-PAHs were analyzed by a gas chromatography flame ionization detector (GC/FID) (Agilent 6890N). The details of the analysis method could be found in previous studies (Kuo et al. 2014; Samaksaman et al. 2015). Furthermore, ash samples were subjected to digestion with a mixture of acids $\left(\mathrm{HCl} / \mathrm{HNO}_{3}=1: 2\right)$ using a microwave-assisted digestion (CEM Mars 5). The digested solution was filtrated through a cellulose filter and diluted with deionized water. The concentration of $\mathrm{Cd}, \mathrm{Cr}, \mathrm{Cu}$, and $\mathrm{Pb}$ was measured by the flame atomic absorption spectroscopy (FAAS) (PerkinElmer AAnalyst 200). X-ray powder diffractometer (XRD) (Shimadza XD-5) was used to determine the crystallinity of treated soil. The chemical states of heavy metals were obtained by the electron spectroscopy for chemical analysis (ESCA) (VersaProbe ULVAC-PHI PHI 5000).

\section{Results and discussion}

\section{Incinerator modes for determining BTEX and PAH emissions}

The experimental results for total concentration of BTEX and 16-PAHs (i.e., naphthalene, acenaphthene, acenaphthylene, fluorene, phenanthrene, anthracene, pyrene, fluoranthene, 2-bromonaphthalene, benz(a)anthracene, chrysene, benzo(a)pyrene, benzo(b)fluoranthene, indeno(1,2,3-cd)pyrene, benzo(g,h,i)perylene, and dibenz(a,h)anthracene) were determined in gaseous phase and bottom ash. These results were obtained in the modes of fixed bed and fluidized bed with different ratios of $S_{\mathrm{a}} / S_{\mathrm{f}}$. Figure 2a shows the plot of total concentration of BTEX and PAHs emitted in gaseous emission. Results of total concentration of BTEX and PAHs from fixed bed and fluidized bed reactors were in the range of $110.7-194.3$ and $88.3-111.7 \mathrm{mg} / \mathrm{Nm}^{3}$, respectively. As shown in the graph, total concentration of BTEX and PAHs in gaseous emission was obviously increased with the alteration of reactor modes from fluidized bed to fixed bed. As Rink et al. (1993) suggest, the process of sewage sludge incineration in a fluidized bed reactor was resulted in the reduction in hydrocarbons and $\mathrm{CO}$ emissions when increasing the supercritical air velocity at the secondary air input. Total concentration of BTEX and PAHs during fluidized bed mode showed similar trends in all cases of $S_{\mathrm{a}} / S_{\mathrm{f}}$ ratios. The increase in $S_{\mathrm{a}} / S_{\mathrm{f}}$ ratios caused a decrease in freeboard region above the sand bed and revealed the reduction in residence time. In addition, at a higher ratio of $S_{\mathrm{a}} / S_{\mathrm{f}}$ fixed bed mode tended to generate $\mathrm{CO}$ emission and resulted in the reduction in combustion efficiency. It is well known that the combustion efficiency of fixed bed mode is lower than that of fluidized bed mode. However, the results demonstrated that the combustion efficiency of all experiments could reach the range of 98-99.5\%.

Total concentration of BTEX and PAHs in bottom ash samples is shown in Fig. 2b. Trends of BTEX and PAHs in bottom ash were significantly increased when increasing the ratios of $S_{\mathrm{a}} / S_{\mathrm{f}}$ in both fixed bed and fluidized bed modes. A lower ratio of $S_{\mathrm{a}} / S_{\mathrm{f}}(0.75 / 1$ to $1.5 / 1)$ of fixed bed mode showed relatively low BTEX and PAHs in bottom ash. These results showed that the small amount of sand bed mixed together with soil particles as a binary-sized mixture improved the hydrodynamics of a fixed bed reactor. The destruction and removal efficiency increases with reaction rates and diffusion coefficients depend on hydrodynamics of the reactor (Nowak et al. 2011). In contrast, a binary-sized mixture influenced the fluidization quality of a 

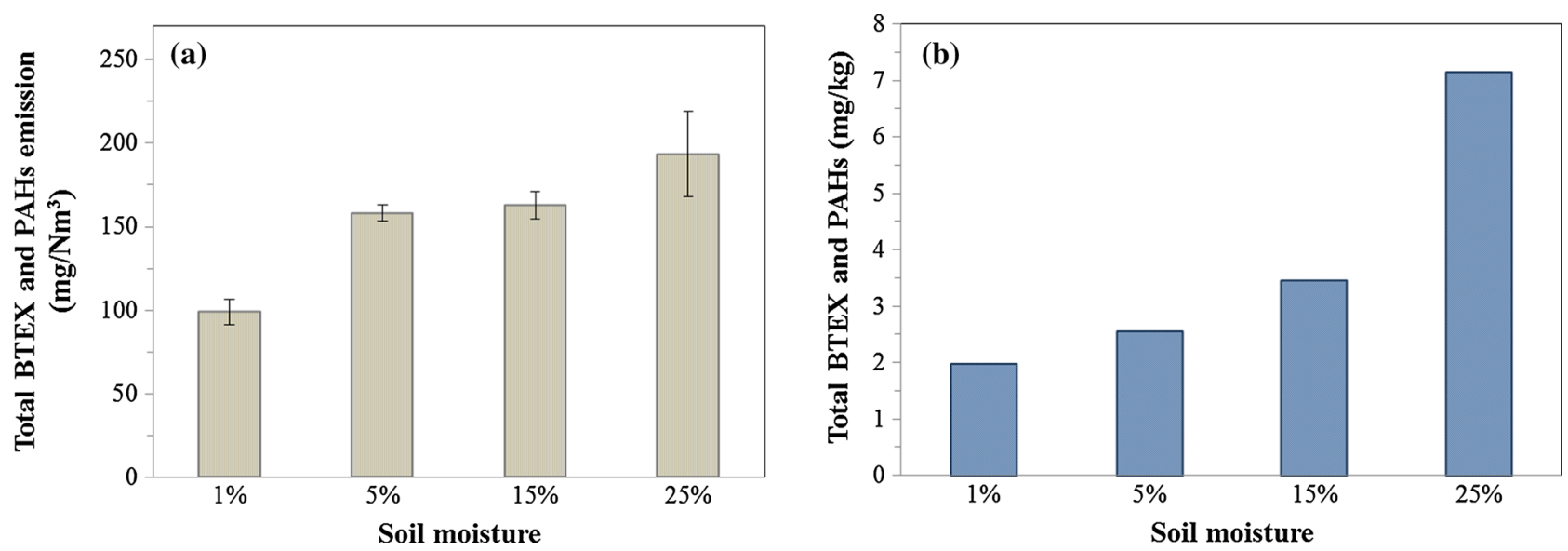

Fig. 3 Effect of moisture content on total concentration of BTEX and PAHs in a gaseous emission and $\mathbf{b}$ bottom ash
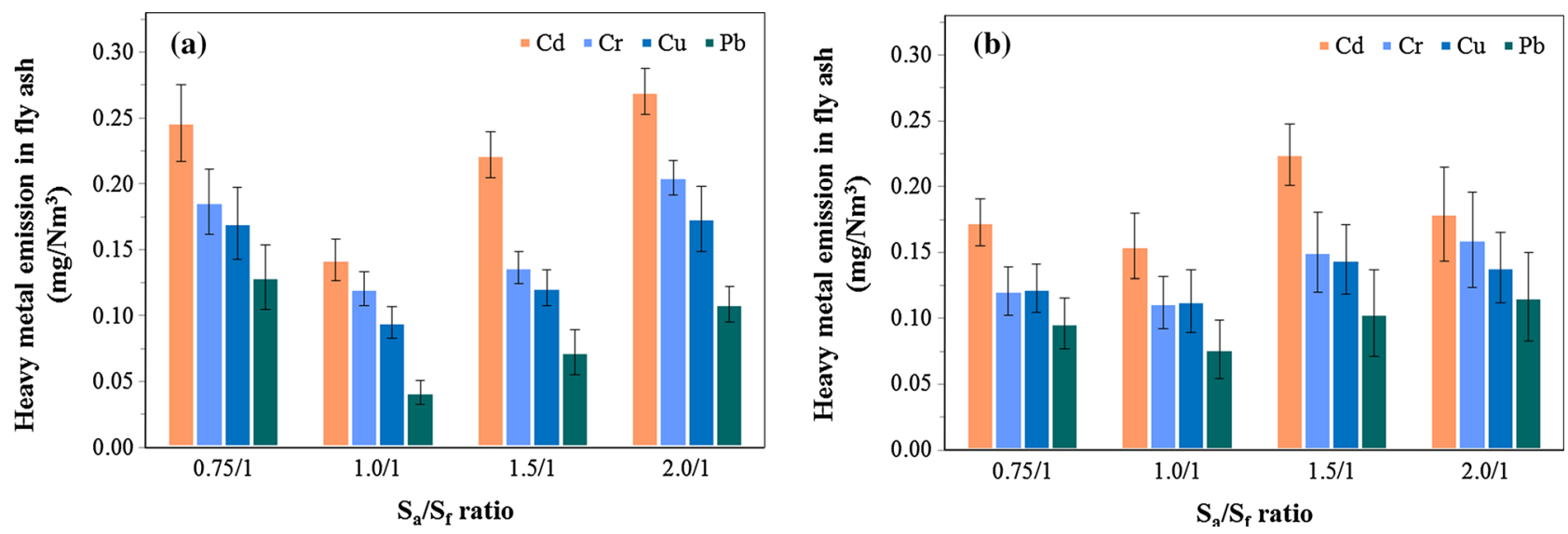

Fig. 4 Effect of $S_{\mathrm{a}} / S_{\mathrm{f}}$ ratio on concentration of heavy metals in fly ash from a fixed bed and $\mathbf{b}$ fluidized bed

fluidized bed reactor (Kuo et al. 2014) and led to the formation of BTEX and PAHs as seen at a higher ratio of $S_{\mathrm{a}} / S_{\mathrm{f}}$ (1.5/1 and 2.0/1) of fluidized bed mode. Total concentration of BTEX and PAHs detected in bottom ash samples were in the ranges of $0.63-3.98 \mathrm{mg} / \mathrm{kg}$ in fixed bed and $1.29-3.36 \mathrm{mg} / \mathrm{kg}$ in fluidized bed modes.

\section{The effect of moisture content on BTEX and PAH emissions}

The experimental results obtained from thermal treatment of co-contaminated soil with different levels of moisture content in a fluidized bed incinerator (with parameters e.g., at temperature of $800{ }^{\circ} \mathrm{C}, S_{\mathrm{a}} / S_{\mathrm{f}}$ ratio of $1.0 / 1$, and fluidization air velocity of $13.65 \mathrm{~cm} / \mathrm{s}$ ). Figure 3 a shows the plot of the effect of moisture content on total concentration of BTEX and PAHs in gaseous emission. From this figure, it is evident that the soil moisture content has an effect on BTEX and PAHs in gaseous emission. Furthermore, CO concentration was found relatively high in gaseous emission when moisture contents in the soil increased.
Therefore, the results of combustion efficiency were decreased. Figure $3 \mathrm{~b}$ shows the effect of moisture content on total concentration of BTEX and PAHs in bottom ash samples. At a higher moisture content (up to $15 \%$ ), BTEX and PAH remained in bottom ash tended to increase. The influence of moisture content, with respect to the steamstripping reaction, was associated with the release of volatile and non-volatile organic compounds such as petroleum hydrocarbons, humus, and toxic organic substances (Huang et al. 2011). This factor contributed to completely remove a persistent lube oil from soil matrix. The finding was also visible in the results of the loss on ignition of bottom ash samples which represented the data sets of the destruction and removal efficiency (DRE) in the range of 99.4-99.9\%.

\section{Incinerator modes for determining of heavy metals in fly ash}

Figure 4 shows the effects of reactor mode and ratio of $S_{\mathrm{a}} / S_{\mathrm{f}}$ on concentration of heavy metals in fly ash. As showed in 

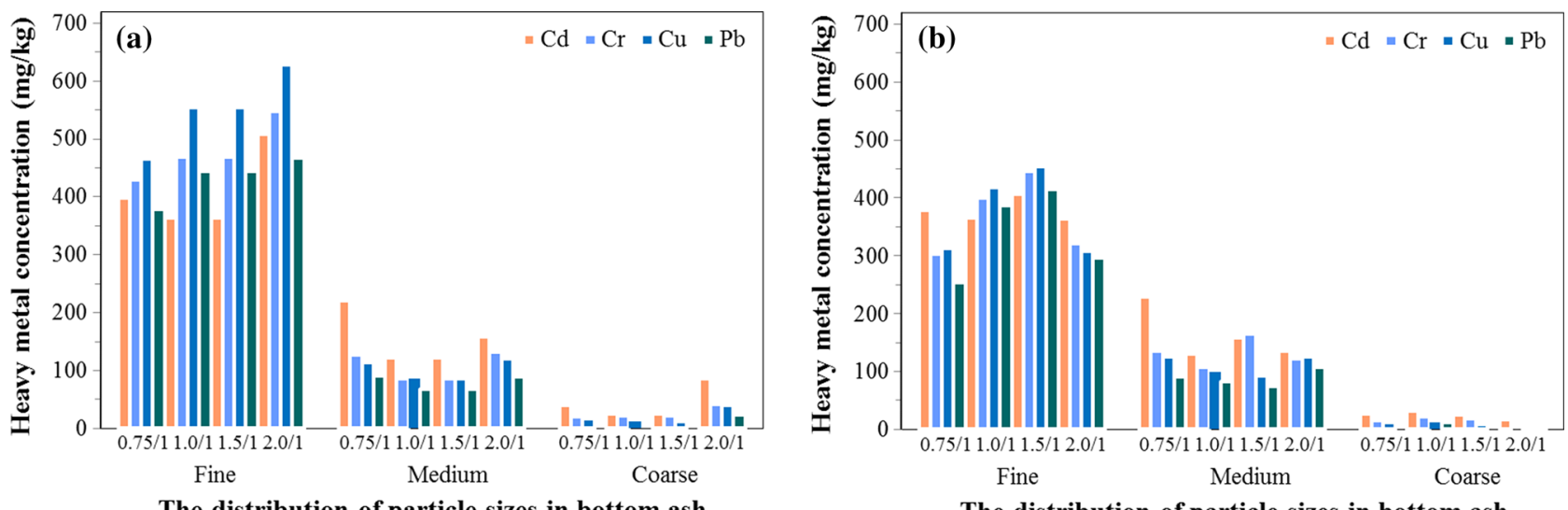

Fig. 5 Partitioning of heavy metals in bottom ash with the distribution of particle sizes of a fixed bed and $\mathbf{b}$ fluidized bed

graphs, in almost of all ratios of $S_{\mathrm{a}} / S_{\mathrm{f}}$, heavy metals in fly ash seemed to decrease with the alteration of reactor modes from fluidized bed to fixed bed. Figure $4 \mathrm{a}$, $\mathrm{b}$ shows that the concentrations of $\mathrm{Cd}, \mathrm{Cr}, \mathrm{Cu}$, and $\mathrm{Pb}$ in fly ash were randomly concentrated. By comparison, their concentrations were in the following order: $\mathrm{Cd}>\mathrm{Cr}>\mathrm{Cu}>\mathrm{Pb}$. Previous studies pointed out that heavy metals evaporated at temperatures near the boiling point of their elements or compounds which were arranged in order of $\mathrm{Cd}>\mathrm{Pb}>\mathrm{Zn}>$ $\mathrm{Cr}>\mathrm{Cu}>\mathrm{Mn}>\mathrm{Ni}$ (Chen and Yan 2012; Ho et al. 1995). However, the results of this study were insufficient proof of the rates of heavy metals volatilization and reaction during soil incineration. In addition, the lowest concentration of heavy metals in fly ash was found at a ratio of $S_{\mathrm{a}} / S_{\mathrm{f}}$ of 1.0/1 in both fixed bed and fluidized bed modes. In particular, the concentration of $\mathrm{Pb}$ was in the range of $0.042-0.077 \mathrm{mg} /$ $\mathrm{Nm}^{3}$. In fluidized bed mode, the concentration of $\mathrm{Cd}$ in fly ash tended to increase when elevating the ratios of $S_{\mathrm{a}} / S_{\mathrm{f}}$ from $1.0 / 1$ to $2.0 / 1$ as $\mathrm{Cd}$ concentrations increased from 0.155 to $0.224 \mathrm{mg} / \mathrm{Nm}^{3}$. The relative quantity of $\mathrm{Cr}$ and $\mathrm{Cu}$ in fly ash of both fixed bed and fluidized bed modes showed

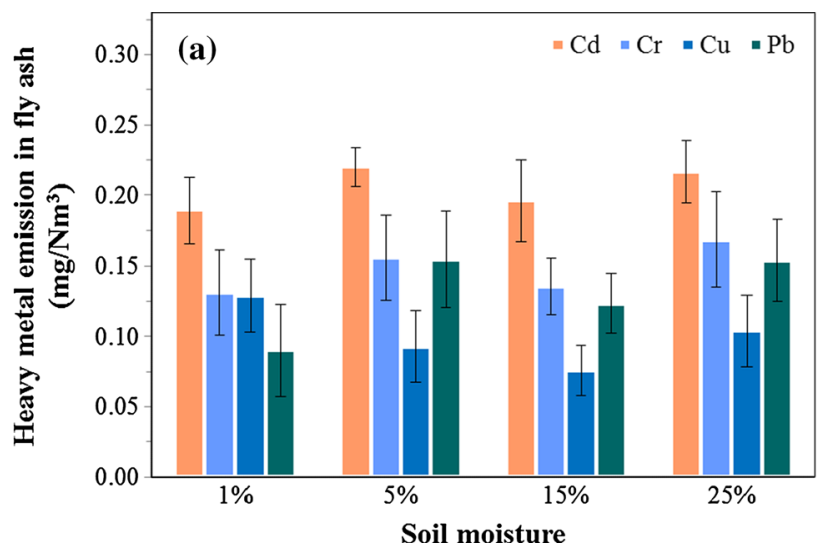

similar trends, but overall, the concentrations of $\mathrm{Cr}$ and $\mathrm{Cu}$ became low in a fluidized bed reactor.

\section{Heavy metals distribution in different bed particle sizes}

Figure 5 shows the distribution of particle sizes in bottom ash samples after thermally treating the co-contaminated soil. Bottom ash of both fixed bed and fluidized bed reactors was divided into three fractions: fine-sized (53-297 $\mu \mathrm{m})$, medium-sized (297-422 $\mu \mathrm{m})$, and coarse-sized particles $(422-1000 \mu \mathrm{m})$. Previous studies reported that the combustion at a high-temperature fluidized bed reactor leads to sand bed attrition and decreased particle size (Lin and Wey 2004a). In fact, heavy metals absorption has strongly affected the particle size and the absorption efficiency varies depending on the specific surface area (Lin 2013). From the results of Lin and Yeh, a smaller particle has a larger specific surface area (Lin and Yeh 2010). Total concentration of heavy metals distributed in various particle size fractions and had a result of the highest concentration of heavy metals within the fine-sized

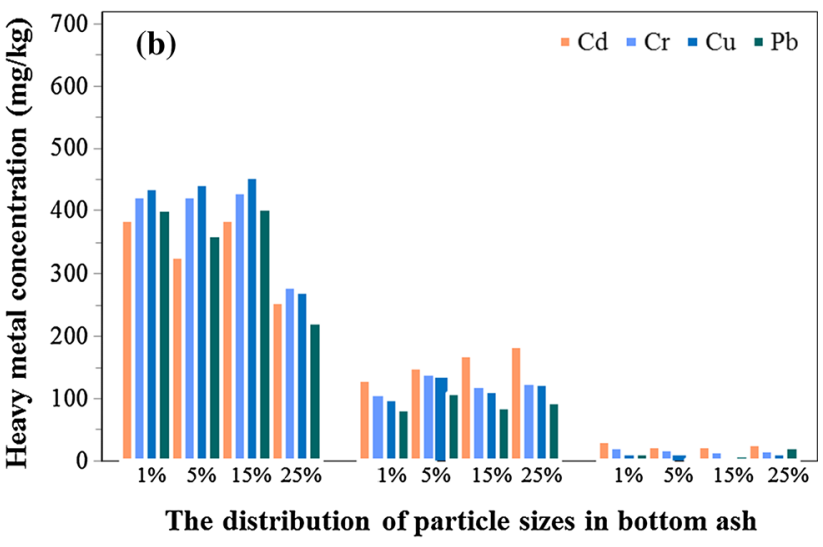

Fig. 6 Effect of moisture content on a concentration of heavy metals in fly ash and $\mathbf{b}$ the partitioning of heavy metals in bottom ash with the distribution of particle sizes 


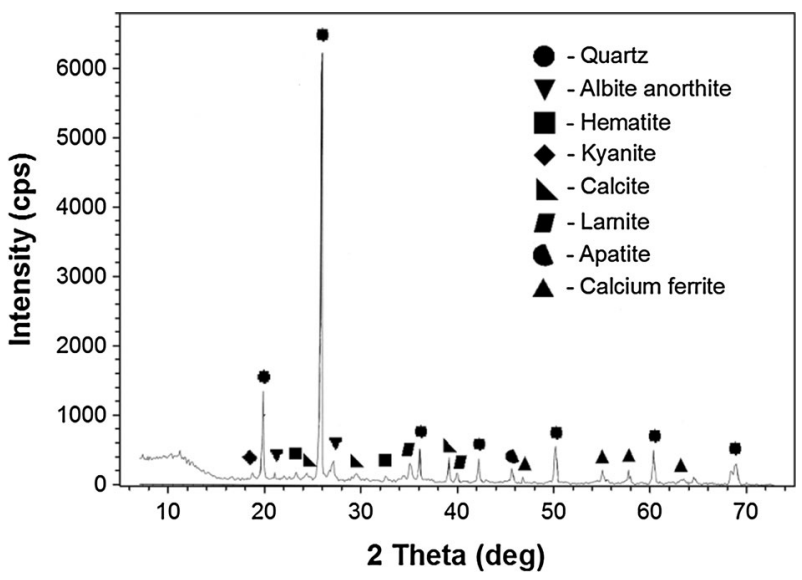

Fig. 7 An XRD spectrum of treated soil (fine-sized particle)

particle. The appearance of a larger particle (medium-sized particle) might be caused by soil-sand and/or soil-soil aggregation in the high-temperature environment (Kuo et al. 2011). On the other hand, the growth of medium-sized particles contaminated with heavy metals might be caused by the broken sands formed with discharged heavy metals during thermally treated co-contaminated soil. Most of used sand became coarse-sized particle. Total concentration of heavy metals in coarse-sized particle could be resulted from liquid eutectics formation (Lin and Yeh 2010). Eutectics formed in terms of heavy metals coating or adhere on the surfactant of sand. Moreover, alkali metals, mineral matters, and metal elements may be a cause of increasing rate of aggregation. As the operating temperature exceeds the melting point of these compounds, they melt and flow over the surface of sand and other particles (Lin et al. 2009).
Heavy metals remained in different particle sizes of bottom ash of both fixed bed and fluidized bed reactors are shown in Fig. 5a, b. The results indicated that concentration of heavy metals in the fine-sized particle of fluidized bed was lower than of fixed bed due to good mixing of reactants by fluidization system (Wei 1996). The lowest concentrations of $\mathrm{Cd}, \mathrm{Cr}, \mathrm{Cu}$, and $\mathrm{Pb}$ in fluidized bed were $364,320,307$, and $297 \mathrm{mg} / \mathrm{kg}$, respectively, and in fixed bed were 399, 429, 465 , and $379 \mathrm{mg} / \mathrm{kg}$, respectively. As seen in figures, the ratios of $S_{\mathrm{a}} / S_{\mathrm{f}}$ not affected the concentrations of heavy metals due to the unpredicted results. Furthermore, the experimental results indicated that both reactors had no effect on the bed agglomeration/defluidization.

\section{The effects of moisture content on heavy metals in fly ash and in different bed particle sizes}

Figure 6a shows the effect of moisture content on concentration of heavy metals in fly ash samples. The vaporized water from the soil during high-temperature environment influences the rate of steam-stripping reaction, but overall, the vaporized water does not enhance the volatilization of heavy metals (Meng et al. 2012). The concentrations of $\mathrm{Cd}$ and $\mathrm{Cr}$ in fly ash remained relatively constant at various moisture contents as average values of $\mathrm{Cd} 0.20 \mathrm{mg} / \mathrm{Nm}^{3}$ and $\mathrm{Cr} 0.15 \mathrm{mg} / \mathrm{Nm}^{3}$. The concentration of $\mathrm{Cu}$ decreased from 0.15 to $0.06 \mathrm{mg} / \mathrm{Nm}^{3}$ with increasing moisture content from 1 to $15 \%$. The concentration of $\mathrm{Pb}$ was gradually increased till the highest moisture content. Figure $6 \mathrm{~b}$ shows the effect of moisture content on the partitioning of $\mathrm{Cd}, \mathrm{Cr}, \mathrm{Cu}$, and $\mathrm{Pb}$ in different particle sizes of bottom ash samples. For finesized particles, concentration of heavy metals was
Table 2 ESCA of major constituents with binding energy shifts

\begin{tabular}{|c|c|c|c|c|c|}
\hline Metal & Core level & Peak $^{\mathrm{a}}$ & Possible species ${ }^{\mathrm{b}}$ & Binding energy $(\mathrm{eV})$ & FWHM $^{\mathrm{c}}$ \\
\hline \multirow[t]{2}{*}{$\mathrm{Cd}$} & \multirow[t]{2}{*}{$\mathrm{Cd} 3 \mathrm{~d} 5$} & (i) & $\mathrm{CdO}, \mathrm{Cd}$ & $405.2 \pm 0.1$ & 1.7040 \\
\hline & & (ii) & $\mathrm{Cd}, \mathrm{Cd}(\mathrm{OH})_{2}, \mathrm{CdCO}_{3}$ & $405.5 \pm 0.1$ & 3.2510 \\
\hline \multirow[t]{2}{*}{$\mathrm{Cr}$} & \multirow[t]{2}{*}{$\mathrm{Cr} 2 \mathrm{p} 3$} & (iii) & $\mathrm{Cr}_{2} \mathrm{O}_{3}, \mathrm{CrO}_{2}, \mathrm{CrO}_{3}$ & $576.8 \pm 0.1$ & 2.7281 \\
\hline & & (iv) & $\mathrm{Cr}_{2} \mathrm{O}_{3}, \mathrm{CrO}_{\mathrm{x}}, \mathrm{Cr}(\mathrm{OH})_{3}, \mathrm{CrO}_{3}$ & $577.4 \pm 0.1$ & 2.1793 \\
\hline \multirow[t]{2}{*}{$\mathrm{Cu}$} & \multirow[t]{2}{*}{$\mathrm{Cu} 2 \mathrm{p} 3$} & (v) & $\mathrm{Cu}_{2} \mathrm{O}, \mathrm{Cu}, \mathrm{Cu}_{3} \mathrm{O}_{2}, \mathrm{CuO}, \mathrm{Cu}$-metal & $932.5 \pm 0.2$ & 2.2441 \\
\hline & & (vi) & $\mathrm{Cu}_{2} \mathrm{O}, \mathrm{CuO}, \mathrm{Cu}, \mathrm{CuFe}_{2} \mathrm{O}_{4}, \mathrm{Al}_{2} \mathrm{Cu}$ & $932.7 \pm 0.1$ & 3.1600 \\
\hline \multirow[t]{2}{*}{$\mathrm{Pb}$} & \multirow[t]{2}{*}{$\mathrm{Pb} 4 \mathrm{f} 7$} & (vii) & $\mathrm{Pb}\left(\mathrm{NO}_{3}\right)_{2}, \mathrm{~Pb}_{3} \mathrm{O}_{4}, \mathrm{PbO}_{2}, \mathrm{PbO}$ & $138.5 \pm 0.2$ & 2.0124 \\
\hline & & (viii) & $\mathrm{PbSiO}_{3}, \mathrm{PbO}, \mathrm{Pb}_{2} \mathrm{PbX}_{2}\left(\mathrm{X:} \mathrm{Cl}^{-}, \mathrm{F}^{-}\right)$ & $139.7 \pm 0.1$ & 3.0387 \\
\hline
\end{tabular}

(i), (iii), (v), (vii) = Possible metal oxide species found in co-contaminated soil

(ii), (iv), (vi), (viii) = Possible metal oxide species found in treated soil

$\mathrm{Cd} 3 \mathrm{~d} 5=$ The core level of cadmium

$\mathrm{Cr} 2 \mathrm{p} 3=$ The core level of chromium

$\mathrm{Cu} 2 \mathrm{p} 3=$ The core level of copper

$\mathrm{Pb} 4 \mathrm{f} 7=$ The core level of lead

a The interpretation of peaks from Fig. 8a, b

b Source from ESCA database (http://www.lasurface.com/database/elementxps.php)

${ }^{c}$ FWHM $=$ The full width at half maximum is determined by the lifetime of the core level 
significantly lower in the soil with $25 \%$ of moisture content. Although the results of heavy metals at $25 \%$ of moisture content were not ruled out, another suggestion might be the effect of moisture contents from 1 to $15 \%$. The concentrations of $\mathrm{Cu}$ and $\mathrm{Cr}$ were gradually increased and $\mathrm{Pb}$ relatively stable. The concentration of $\mathrm{Cd}$ was slightly decreased. Previous studies indicated that the combustion of sludge contained highly moisture had little effect on the reductionoxidation reactions of metal elements in bottom ash due to metal elements associated with $\mathrm{Fe}$ and Mn oxides (Chen and Yan 2012). Moreover, this would explain the relationship between water and kaolinite in soil, which might contribute to the capture of metals (especially $\mathrm{Cu}$ ) during combustion (Folgueras et al. 2007). $\mathrm{Cu}$ is mainly associated with iron (Fe) and clay minerals, which enhance the ionic strength of metal-clay sorption formation (Wei 1996). The low-volatile metals (e.g., $\mathrm{Cu}, \mathrm{Cr}, \mathrm{Mn}, \mathrm{Ni}$ ) were presented in their metal oxide forms, which were mainly eutectic and intercepted in the bottom ash. The conversion of low-volatile metals from metal elements to metal oxide species reveals with the rates of fixation and immobility (Lin et al. 2009; Lin and Peng 2012; Lin and Wey 2004b).

\section{Ash characterizations}

To understand mineral components, eutectic species, and surface chemistry of co-contaminated soil and treated soil (fine-sized particle) from a fluidized bed reactor, XRD and ESCA techniques were used. In fact, an XRD spectrum of treated soil sample from both fixed bed and fluidized bed had a similarity. The wide-scan XRD spectrum of treated soil is shown in Fig. 7. As shown in the XRD plot, the heavy metals on the particle surfactant were not detected due to much lower concentrations than the detection limit (Lin and Yeh 2010). The plot of minerals indicates that a cluster of points around two-theta $(2 \theta)$ of $20^{\circ}-70^{\circ}$. Minerals such as quartz $\left(\mathrm{SiO}_{2}\right)$,

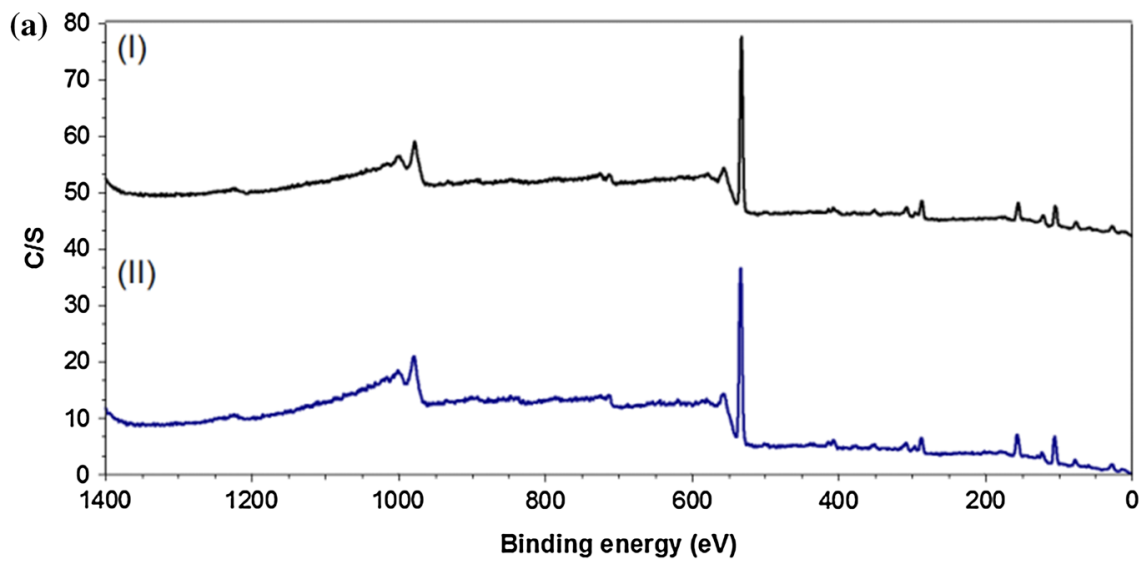

(b)
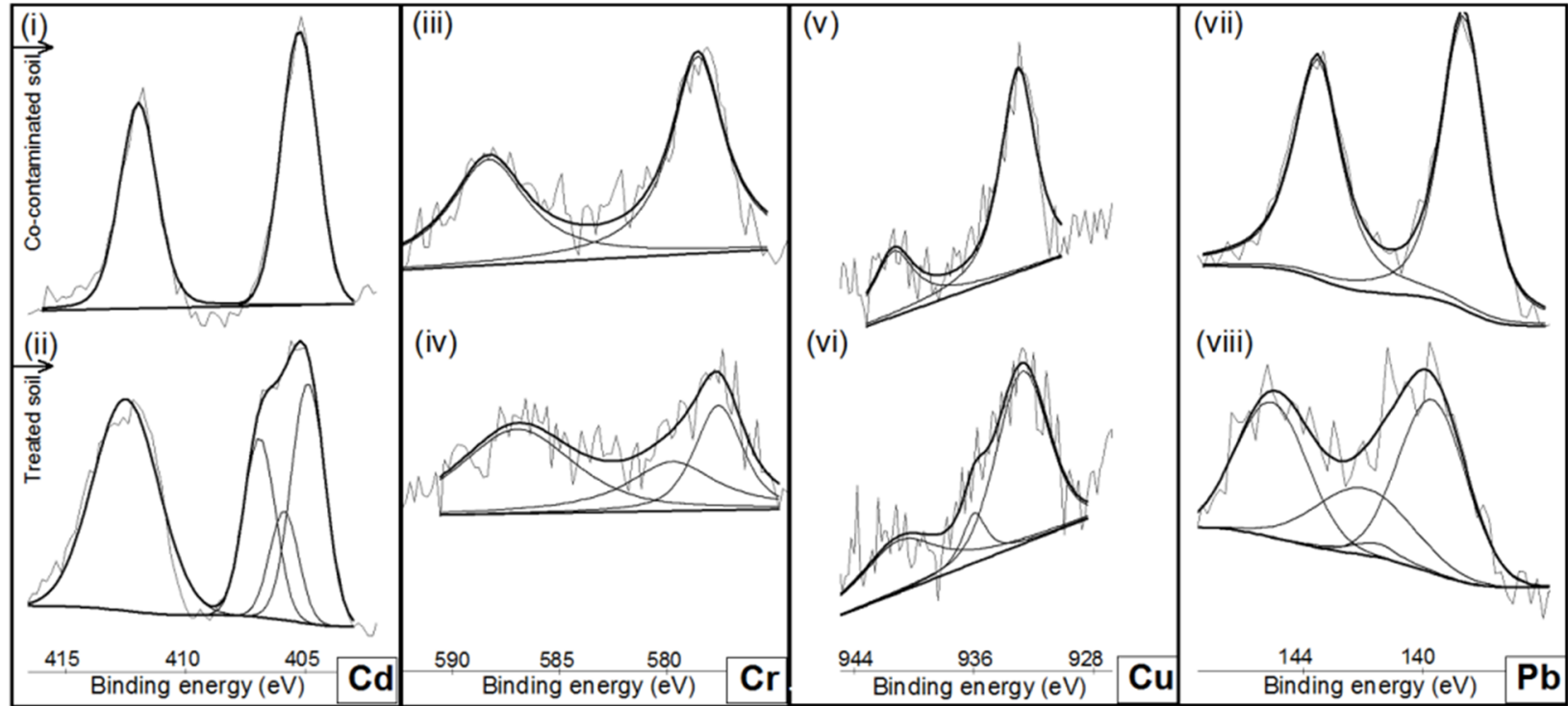

Fig. 8 ESCA plots of a wide-scan spectra of (i) co-contaminated soil and (ii) treated soil and $\mathbf{b}$ high-resolution spectra of co-contaminated soil and treated soil in terms of binding energy analysis for $(i, i i) \mathrm{Cd}$, (iii, iv) $\mathrm{Cr},(v, v i) \mathrm{Cu}$, and (vii, viii) $\mathrm{Pb}$ 
albite-anorthite $\left(\mathrm{NaAlSi}_{3} \mathrm{O}_{8}-\mathrm{CaAl}_{2} \mathrm{Si}_{2} \mathrm{O}_{8}\right)$, hernatite $\left(\mathrm{Fe}_{2} \mathrm{O}_{3}\right)$, kyanite $\left(\mathrm{Al}_{2} \mathrm{SiO}_{5}\right)$, calcite $\left(\mathrm{CaCO}_{3}\right)$, larnite $\left(\mathrm{Ca}_{2} \mathrm{SiO}_{4}\right)$, apatite $\left(\mathrm{Ca}_{5}\left(\mathrm{PO}_{4}\right)_{3}\right)$, and calcium ferrite $\left(\mathrm{Ca}_{2} \mathrm{Fe}_{2} \mathrm{O}_{5}\right)$ were investigated. $\mathrm{Al}, \mathrm{Si}$, and $\mathrm{Ca}$ compounds were presented as the main species in treated soil particle (Folgueras et al. 2007; Tang et al. 2013; Xu et al. 2013). This result suggests that silicate and aluminosilicate frameworks are intact after combustion (Benson et al. 1995).

ESCA was used to determine eutectic species and surface chemistry. The analytical procedure can be referred from previous work (Kuo et al. 2010). The possible species found in co-contaminated soil and treated soil (fine-sized particle) surfactants are listed in Table 2. Figure 8a illustrates the wide-scan ESCA spectra of co-contaminated soil and treated soil. At an operating temperature of $800{ }^{\circ} \mathrm{C}$, the combustion promoted the formation of crystalline-amorphous metal oxides which resulted from the aggregation of heavy metals. Binding energy shifts revealed chemical shifts to oxidation state of metal oxides. Figure $8 \mathrm{~b}$ shows binding energy shifts of co-contaminated soil and treated soil. Results of ESCA indicated that major constituents such as $\mathrm{Cd}, \mathrm{CdO}^{-}, \mathrm{CdCO}_{3}$, $\mathrm{Cr}_{2} \mathrm{O}_{3}, \mathrm{CrO}_{x}, \mathrm{CrO}_{3}, \mathrm{Cu}_{2} \mathrm{O}, \mathrm{Cr}(\mathrm{OH})_{3}, \mathrm{CuO}, \mathrm{CuFe}_{2} \mathrm{O}_{4}, \mathrm{Cu}-$ metal, $\mathrm{Al}_{2} \mathrm{Cu}, \mathrm{PbSiO}_{3}$, and $\mathrm{PbO}$ formed during soil combustion. In determining, heavy metal oxide forms have interacted with the individual mineral elements such as $\mathrm{Fe}$, $\mathrm{Al}$, and $\mathrm{Si}$. CuO $\cdot \mathrm{Fe}_{2} \mathrm{O}_{3}, \mathrm{CdO} \cdot \mathrm{Fe}_{2} \mathrm{O}_{3}, \mathrm{CdO} \cdot \mathrm{SiO}_{2}, \mathrm{PbO} \cdot \mathrm{SiO}_{2}$, and $\mathrm{PbO} \cdot \mathrm{Al}_{2} \mathrm{O}_{3}$ were taken into account for eutectic species analysis. The formation of $\mathrm{Cr}$ with $\mathrm{Ca}$ element was found in terms of $\mathrm{CaO} \cdot \mathrm{Cr}_{2} \mathrm{O}_{3}$ (Folgueras et al. 2007).

\section{Conclusion}

This study considered the effect of co-contaminated soil mixtures as fixed/fluidized bed media, which was a comparative study with different ratios of $S_{\mathrm{a}} / S_{\mathrm{f}}$. In addition, the effect of soil moisture content was further investigated. The data obtained from these examinations can be used to determine pollutants emission from incineration of soil cocontaminated with lube oil and heavy metals. It is possible that high levels of hazardous contaminants in the soil can be achieved using the approaches of thermal treatment under the operating conditions of either fixed bed or fluidized bed incineration. The efficiency of fluidized bed reactor was observed to be higher than of fixed bed reactor. Fluidization behavior plays an important role in emissions of organic pollutants and heavy metals in both gaseous emission and ash residues. In addition, moisture content in the soil affected and directly disturbed the combustion efficiency. Increasing BTEX and PAHs emissions and flue gas (CO) obviously resulted from the combustion of a highly moisture content. The heated water in the soil at $800{ }^{\circ} \mathrm{C}$ produced steam, with respect to steam-stripping reaction, which might affect heavy metals removal and/or fixation and immobilization. Heavy metals in different particle sizes of bottom ash were investigated. The highest concentration of heavy metals is found in the fine-sized particle due to large specific surface area. Moreover, the distribution of heavy metals in medium-sized and coarsesized particles to form eutectic species might be obtained by the soil-sand aggregation.

Acknowledgments Financial support from the Taiwan National Science Council, the Grant number: NSC-101-2221-E-033-081, is gratefully acknowledged.

\section{References}

Abdulsalam S, Bugaje IM, Adefila SS, Ibrahim S (2011) Comparison of biostimulation and bioaugmentation for remediation of soil contaminated with spent motor oil. Int J Environ Sci Technol 8(1):187-194

Acharya P, Fogo D, McBride C (1996) Process challenges in rotary kiln-based incinerators in soil remediation projects. Environ Prog 15(4):267-276

Alisi C, Musella R, Tasso F, Ubaldi C, Manzo S, Cremisini C, Sprocati AR (2009) Bioremediation of diesel oil in a cocontaminated soil by bioaugmentation with a microbial formula tailored with native strains selected for heavy metals resistance. Sci Total Environ 407(8):3024-3032

Alloway B (2013) Sources of heavy metals and metalloids in soils: heavy metals in soils. Springer, The Netherlands, pp 11-50

Almeida R, Mucha A, Teixeira C, Bordalo A, Almeida CM (2013) Biodegradation of petroleum hydrocarbons in estuarine sediments: metal influence. Biodegradation 24(1):111-123

Benson SA, Sondreal EA, Hurley JP (1995) Status of coal ash behavior research. Fuel Process Technol 44(1-3):1-12

Bolan N, Kunhikrishnan A, Thangarajan R, Kumpiene J, Park J, Makino T, Kirkham MB, Scheckel K (2014) Remediation of heavy metal(loid)s contaminated soils-to mobilize or to immobilize? J Hazard Mater 266:141-166

Bradl HB (2005) Chapter 1 sources and origins of heavy metals: Heavy metals in the environment. Elsevier, Germany, pp 1-27

Bulmău C, Mărculescu C, Lu S, Qi Z (2014) Analysis of thermal processing applied to contaminated soil for organic pollutants removal. J Geochem Explor 147:298-305

Chen T, Yan B (2012) Fixation and partitioning of heavy metals in slag after incineration of sewage sludge. Waste Manag 32(5):957-964

Eldabbagh F, Ramesh A, Hawari J, Hutny W, Kozinski JA (2005) Particlemetal interactions during combustion of pulp and paper biomass in a fluidized bed combustor. Combust Flame 142(3):249-257

Falciglia PP, Giustra MG, Vagliasindi FGA (2011) Low-temperature thermal desorption of diesel polluted soil: influence of temperature and soil texture on contaminant removal kinetics. J Hazard Mater 185(1):392-400

Folgueras MB, Díaz RM, Xiberta J, Alonso M (2007) Effect of inorganic matter on trace element behavior during combustion of coal-sewage sludge blends. Energy Fuels 21(2):744-755

Fuentes MJ, Font R, Gómez-Rico MF, Martín-Gullón I (2007) Pyrolysis and combustion of waste lubricant oil from diesel cars: decomposition and pollutants. J Anal Appl Pyrol 79(1-2):215-226

González-Corrochano B, Alonso-Azcárate J, Rodas M (2012) Effect of thermal treatment on the retention of chemical elements in the structure of lightweight aggregates manufactured from contaminated mine soil and fly ash. Constr Build Mater 35:497-507 
Ho TC, Lee HT, Shiao CC, Hopper JR, Bostick WD (1995) Metal behavior during fluidized bed thermal treatment of soil. Waste Manag 15(5-6):325-334

Hu G, Li J, Zeng G (2013) Recent development in the treatment of oily sludge from petroleum industry: a review. J Hazard Mater 261:470-490

Huang Y-T, Hseu Z-Y, Hsi H-C (2011) Influences of thermal decontamination on mercury removal, soil properties, and repartitioning of coexisting heavy metals. Chemosphere 84(9):1244-1249

Jones FC, Blomqvist EW, Bisaillon M, Lindberg DK, Hupa M (2013) Determination of fossil carbon content in swedish waste fuel by four different methods. Waste Manag Res 31(10):1052-1061

Khan FI, Husain T, Hejazi R (2004) An overview and analysis of site remediation technologies. J Environ Manag 71(2):95-122

Koning M, Hupe K, Stegmann R (2000) Thermal processes, scrubbing/extraction, bioremediation and disposal, in biotechnology: environmental processed II. Wiley-VCH Verlag $\mathrm{GmbH}$, Germany, pp 304-317

Kuo J-H, Wey M-Y, Lin C-L, Chiu H-M (2008) The effect of aluminum inhibition on the defluidization behavior and generation of pollutants in fluidized bed incineration. Fuel Process Technol 89(11):1227-1236

Kuo J-H, Lin C-L, Wey M-Y (2010) Mechanisms of particle agglomeration and inhibition approach in the existence of heavy metals during fluidized bed incineration. Chem Eng Sci 65(17):4955-4966

Kuo J-H, Lin C-L, Wey M-Y (2011) Effect of alkali concentrations and operating conditions on agglomeration/defluidization behavior during fluidized bed air gasification. Powder Technol 214(3):443-446

Kuo J-H, Wey M-Y, Lian Y-H, Samaksaman U (2014) Gaseous organic emissions during air gasification of woody waste: effect of bed agglomeration/defluidization. Fuel Process Technol 128:104-110

Lin C-L (2013) Effects of fluidized parameters on capture of heavy metal in various bed-material size distributions. Fuel Process Technol 106:149-159

Lin C-L, Peng T-H (2012) Evaluation of heavy metal distribution and biological toxicity in agglomeration bed material during artificial waste incineration in fluidized bed. Korean $\mathrm{J}$ Chem Eng 29(5):627-635

Lin C-L, Wey M-Y (2004a) Statistical and power spectral analysis of quality of fluidization for different particle size distributions at high temperature. Adv Powder Technol 15(1):79-96

Lin C-L, Wey M-Y (2004b) The effect of mineral compositions of waste and operating conditions on particle agglomeration/ defluidization during incineration. Fuel 83(17-18):2335-2343

Lin C-L, Yeh TY (2010) Heavy metals distribution characteristics in different particle size of bottom ash after agglomeration/ defluidization at various fluidization parameters. Biomass Bioenergy 34(4):428-437

Lin C-L, Kuo J-H, Wey M-Y, Chang S-H, Wang K-S (2009) Inhibition and promotion: the effect of earth alkali metals and operating temperature on particle agglomeration/defluidization during incineration in fluidized bed. Powder Technol 189(1):57-63

Mascolo G, Rausa R, Bagnuolo G, Mininni G, Tinucci L (2006) Thermal degradation of synthetic lubricants under oxidative pyrolytic conditions. J Anal Appl Pyrol 75(2):167-173

Meng A, Li Q, Jia J, Zhang Y (2012) Effect of moisture on partitioning of heavy metals in incineration of municipal solid waste. Chin J Chem Eng 20(5):1008-1015

Mininni G, Sbrilli A, Guerriero E, Rotatori M (2004) Polycyclic aromatic hydrocarbons formation in sludge incineration by fluidised bed and rotary kiln furnace. Water Air Soil Pollut 154(1-4):3-18

Nordmark D, Kumpiene J, Andreas L, Lagerkvist A (2011) Mobility and fractionation of arsenic, chromium and copper in thermally treated soil. Waste Manag Res 29(1):3-12
Nowak B, Perutka L, Aschenbrenner P, Kraus P, Rechberger H, Winter F (2011) Limitations for heavy metal release during thermo-chemical treatment of sewage sludge ash. Waste Manag 31(6):1285-1291

Osman KT (2014) Soil pollution. In: soil degradation, conservation and remediation, chap 6 . Springer, The Netherlands, pp 149-226

Peng T-H, Lin C-L (2014) Influence of various chlorine additives on the partitioning of heavy metals during low-temperature twostage fluidized bed incineration. J Environ Manag 146:362-368

Qi Z, Chen T, Bai S, Yan M, Lu S, Buekens A, Yan J, Bulmău C, Li $X$ (2014) Effect of temperature and particle size on the thermal desorption of PCBs from contaminated soil. Environ Sci Pollut Res 21(6):4697-4704

Qin L, Han J, He X, Zhan Y, Yu F (2015) Recovery of energy and iron from oily sludge pyrolysis in a fluidized bed reactor. J Environ Manag 154:177-182

Rink KK, Larsen FS, Kozinski JA, Lighty JS, Silcox GD, Pershing DW (1993) Thermal treatment of hazardous wastes: a comparison of fluidized bed and rotary kiln incineration. Energy Fuels 7(6):803-813

Rutkowska B, Bomze K, Szulc W, Gozdowski D, Spychaj-Fabisiak E (2015) Soil factors affecting solubility and mobility of zinc in contaminated soils. Int J Environ Sci Technol 12(5):1687-1694

Samaksaman U, Kuo J, Peng T, Wey M (2015) Determination of emission characteristics during thermal treatment of lube oil and heavy metal co-contaminated soil by fluidized bed combustion. J Environ Eng. doi:10.1061/(ASCE)EE.1943-7870.0000953040 15024

Tang P, Zhou Y, Xie Z (2013) Effects of hydroxyapatite addition on heavy metal volatility during tannery sludge incineration. Environ Sci Pollut Res 20(7):4405-4413

Taube F, Pommer L, Larsson T, Shchukarev A, Nordin A (2008) Soil remediation-mercury speciation in soil and vapor phase during thermal treatment. Water Air Soil Pollut 193(1-4):155-163

Torres LGB, Climent M, Saquelares J, Bandala ER, Urquiza G, Iturbe R (2007) Characterization and treatability of a contaminated soil from an oil exploration zone. Int J Environ Sci Technol 4(3):311-322

Van Caneghem J, Brems A, Lievens P, Block C, Billen P, Vermeulen I, Dewil R, Baeyens J, Vandecasteele C (2012) Fluidized bed waste incinerators: design, operational and environmental issues. Prog Energy Combust Sci 38(4):551-582

Wei Y-L (1996) Thermal immobilization of lead contaminants in soils treated in a fixed- and fluidized-bed incinerator at moderate temperatures. J Air Waste Manag 46(5):422-429

Wey M-Y, Chao C-Y, Wei M-C, Yu L-J, Liu Z-S (2000) The influence of heavy metals on partitioning of PAHs during incineration. J Hazard Mater 77(1-3):77-87

Wey M-Y, Chen J-C, Wu H-Y, Yu W-J, Tsai T-H (2006) Formations and controls of hcl and PAHs by different additives during waste incineration. Fuel 85(5-6):755-763

Wiłkomirski B, Sudnik-Wójcikowska B, Galera H, Wierzbicka M, Malawska M (2011) Railway transportation as a serious source of organic and inorganic pollution. Water Air Soil Pollut 218(1-4):333-345

Wu M-H, Lin C-L, Zeng W-Y (2014) Effect of waste incineration and gasification processes on heavy metal distribution. Fuel Process Technol 125:67-72

Xu G, Liu M, Li G (2013) Stabilization of heavy metals in lightweight aggregate made from sewage sludge and river sediment. J Hazard Mater 260:74-81

Zhang Y, Li Q, Jia J, Meng A (2012) Thermodynamic analysis on heavy metals partitioning impacted by moisture during the MSW incineration. Waste Manag 32(12):2278-2286 